\title{
Comment on 'Tumour antigen expression in hepatocellular carcinoma in a low-endemic western area'
}

\author{
F Grizzi ${ }^{*}, 1$, D Qehajaj ${ }^{1}$, M Chiriva-Internati ${ }^{2}$ and S Stifter ${ }^{3}$ \\ ${ }^{1}$ Department of Inflammation and Immunology, Humanitas Clinical and Research Center, Rozzano, Milan, Italy; ${ }^{2}$ Kiromic LLC, Houston, TX, USA \\ and ${ }^{3}$ Department of Pathology, Faculty of Medicine, University of Rijeka, Rijeka, Croatia
}

Sir,

We read with great interest the study by Sideras et al (2015) that combines tissue microarrays (TMA) and immunohistochemistry to investigate the expression pattern of 15 antigens belonging to different categories, including cancer testis antigens (CTAs) and oncofetal proteins in primary hepatocellular carcinoma (HCC). Because current therapies for HCC are far from ideal (Ilan, 2014) and immunotherapy has been proposed as a potential therapeutic option, the authors aimed at identifying a panel of relevant tumour antigens with broad expression in a Western European population of HCC patients and specific expression in the tumour tissue (Sideras et al, 2015). Cancer testis antigens represent a family of $>200$ proteins selectively expressed in malignant cells, but not in their natural counterpart except for human germ cells (Simpson et al, 2005; Gjerstorff et al, 2015; Grizzi et al, 2015). Among the different types of tumour antigens, CTAs identified highly promising therapeutic targets (Gjerstorff et al, 2015). In contrast to previous studies (Xu et al, 2012; Liang et al, 2013; Xia et al, 2013; Wang et al, 2015), Sideras et al (2015) found a low ( $<10 \%$ of patients) prevalence of expression of MAGE-A3/4, NY-ESO-1, MAGE-A1 and MAGE-A10. Moreover, a low ( $<10 \%$ of patients) prevalence of expression of the foetal specific glycoprotein alpha-fetoprotein (AFP) was found. Although its serum level falls rapidly after birth and its synthesis in adult life is repressed, $>70 \%$ of HCC-affected patients have usually a high serum concentration of AFP. Today, AFP and ultrasonography are the main tests for HCC surveillance in clinical practice, and in the interim, using ultrasonography and AFP in combination may be the best strategy to optimise early HCC detection (Mehta and Singal, 2015). Sideras et al (2015) stated that the observed prevalence of expression of CTAs and oncofetal antigens was generally lower because previous studies have been conducted in East Asia where hepatitis B virus infection is the prevalent cause of HCC and the majority of HCC patients have liver cirrhosis. Furthermore, previous investigators used RT-PCR measuring mRNA expression, whereas they evaluated protein expression by immunohistochemistry. Here, we would like to discuss additional points underlying these discrepancies and that impact on the CTAs as immunotherapeutic targets. In an effort to accelerate translation of new developments in basic immunology into cancer patients, representatives from eight immunotherapy organisations representing Europe, Japan, China and North America convened an 'Immunotherapy Summit' at the 24th Annual Meeting of the International Society for Biological Therapy of Cancer (now called Society for Immunotherapy of Cancer, SITC). One of the concepts raised by SITC and defined as critical was the need to identify hurdles that impede effective translation of cancer immunotherapy (Fox et al, 2011). The critical hurdles highlighted have been grouped into nine general themes. Among these have been identified the 'complexity of cancer', its 'heterogeneity' and 'immune escape' (Fox et al, 2011). Hepatocellular carcinoma originates and progresses throughout a dynamic process involving different 'driven alterations' that ultimately lead to the malignant transformation of hepatocytes. Malignant transformation may occur regardless of the aetiologic agent through a pathway of increased liver cell turnover, induced by chronic liver injury and regeneration in a context of inflammation, immune response and oxidative DNA damage (Li and Wang, 2015). Hepatocellular carcinoma is a heterogeneous disease in 'space' and in 'time'. The term 'heterogeneity' defines the presence of cell clones, within a tumoral mass, with different genetic aberrations that mediate divergent biology defining the natural history of that particular tumour, that is, one clone does not represent the entirety of the tumour cell population. This variability is what ultimately determines the evolutionary progression of neoplastic disease and its response to therapy (Luo et al, 2009). Singular cells respond differently to the same stimulus, with some not responding at all (Floor et al, 2012; Almendro et al, 2013). These considerations, in conjunction with the complexity of 'tumour-host' interactions caused by temporal changes in tumour phenotypes and an array of immune mediators expressed in the tumour microenvironment, might explain the limited reliability and applicability of current therapeutic strategies. Sideras et al (2015) did not report fundamental hallmarks of cancer, including 'cancer complexity', 'tumour heterogeneity' and 'field cancerization', that is, the presence of abnormal tissue surrounding primary cancerous lesions. These observations lead us to reflect on the appropriateness of TMAs to state the CTAs and oncofetal proteins as potential therapeutic targets. It is known that diagnostic accuracy of a histological assay may be affected if the 'target antigen' is uniquely present in a fraction of a tumour (Sottoriva et al, 2015). Tissue microarray consists of small fractions of tissue inserted into a recipient paraffin block such that a tissue section on a single glass slide can contain numerous patient samples in a spatially structured pattern. Although the study of whole-tissue sections for the evaluation of large tumour cohorts is tedious and costly, the genome-wide network of intra-tumour heterogeneity across multiple spatial and temporal scales, and patientspecific patterns of cancer evolution limits the appropriateness of investigating a small fraction of tissue, and is prone to controversial results and consequences for treatment design (Chiriva-Internati et al, 2004). In addition, Sideras et al (2015) applied a scoring system, called 'H-score' obtained by multiplying the intensity score (range: $0-3$ ) with the level of $\%$ of positive cells, where $1 \leqslant 5 \%, 2=5-25 \%, 3=25-75 \%$ and $4 \geqslant 75 \%$. However, this approach generates equivalent 'mathematical products', (i.e., condition 1: intensity $=1$ multiplied with the level of $\%$ of positive cells $2=5-25 \%$ is the same product obtained multiplying intensity $=2$ with the level of $\%$ of positive cells $1 \leqslant 5 \%$; condition 2 : intensity $=1$ multiplied with the level of $\%$ of positive cells $3=25-75 \%$ is the same product obtained multiplying intensity $=3$ with the level of $\%$ of positive cells $1<5 \%$; condition 3 : intensity $=1$ multiplied with the level of $\%$ of positive cells $4 \geqslant 75 \%$ is the same product obtained multiplying intensity $=2$ with the level of $\%$ of positive cells $2=5-25 \%$; condition 4 : intensity $=2$ multiplied with the level of $\%$ of positive cells $3=25-75 \%$ is the same product obtained multiplying intensity $=3$ with the level of $\%$ of positive cells $2=5-25 \%$ ), although their biological significance is completely different. In other words, these overlapping 'scores' subtend different impacts on the capacity of CTAs to elicit the immune response and the heterogeneous behaviour of HCC. In conclusion, to advance our knowledge in a currently widely debated field of investigation such as that of immunotherapy and HCC, a clearer distinction must be made between the exploration of CTA expression pattern and their real application in human clinical trials. Because the analysis of CTA expression is useful in identifying patients who are most likely to benefit from immune intervention strategies, we need to adopt a more adequate experimental approach and a change in our 'mind' from a 'qualitative' or 'semi-quantitative' to a more advanced 'quantitative' thinking.

\section{CONFLICT OF INTEREST}

The authors declare no conflict of interest.

\section{REFERENCES}

Almendro V, MarusyK A, Polyak K (2013) Cellular heterogeneity and molecular evolution in cancer. Annu Rev Pathol 8: 277-302.

Chiriva-Internati M, Grizzi F, Bright RK, Martin Kast W (2004) Cancer immunotherapy: avoiding the road to perdition. J Transl Med 2: 26.

Floor SL, Dumont JE, Maenhaut C, Raspe E (2012) Hallmarks of cancer: of all cancer cells, all the time? Trends Mol Med 18: 509-515.

Fox BA, Schendel DJ, Butterfield LH, Aamda LS, Allison JP, Ascierto PA, Atkins MB, Bartunkova J, Bergmann L, Berinstein N, Bonorino CC, Borden E, Bramson JL, Britten CM, Cao X, Carson WE, Chang AE, Characiejus D, Choudhury AR, Coukos G, De Gruijl T, Dillman RO, Dolstra H, Dranoff G, Durrant LG, Finke JH, Galon J, Gollob JA, Gouttefangeas C, Grizzi F, Guida M, Hakansson L, Hege K, Herberman RB, Hodi FS, Hoos A, Huber C, 
Hwu P, Imai K, Jaffee EM, Janetzki S, June CH, Kalinski P, Kaufman HL, Kawakami K, Kawakami Y, Keilholtz U, Khleif SN, Kiessling R, Kotlan B, Kroemer G, Lapointe R, Levitsky HI, Lotze MT, Maccalli C, Maio M,

Marschner JP, Mastrangelo MJ, Masucc IG, Melero I, Melief C,

Murphy WJ, Nelson B, Nicolini A, Nishimura MI, Odunsi K, Ohashi PS, O'Donnell-Tormey J, Old LJ, Ottensmeier C, Papamichail M, Parmiani G, Pawelec G, Proietti E, Qin S, REES R, Ribas A, Ridolfi R, Ritter G, Rivoltini L, Romero PJ, Salem ML, Scheper RJ, Seliger B, Sharma P, Shiku H, Singh-Jasuja H, Song W, Straten PT, Tahara H, Tian Z, Van Der Burg SH, Von Hoegen P, Wang E, Welters MJ, Winter H, Withington T, Wolchok JD, Xiao W, Zitvogel L, Zwierzina H, Marincola FM, Gajewski TF, Wigginton JM, Disis ML (2011) Defining the critical hurdles in cancer immunotherapy. J Transl Med 9: 214 .

Gjerstorff MF, Andersen MH, Ditzel HJ (2015) Oncogenic cancer/testis antigens: prime candidates for immunotherapy. Oncotarget 6: 15772-15787.

Grizzi F, Mirandola L, Qehajaj D, Cobos E, Figueroa JA, Chiriva-Internati M (2015) Cancer-testis antigens and immunotherapy in the light of cancer complexity. Int Rev Immunol 34: 143-153.

Ilan Y (2014) Immune therapy for hepatocellular carcinoma. Hepatol Int 8(Suppl 2): 499-504.

Li L, Wang H (2015) Heterogeneity of liver cancer andpersonalized therapy. Cancer Lett; e-pub ahead of print 23 July 2015; doi:10.1016/ j.canlet.2015.07.018.

Liang J, Ding T, Guo ZW, Yu XJ, Hu YZ, Zheng L, Xu J (2013) Expression pattern of tumour-associated antigens in hepatocellular carcinoma: association with immune infiltration and disease progression. Br J Cancer 109: 1031-1039.
Luo J, Solimini NL, Elledge SJ (2009) Principles of cancer therapy: oncogene and non-oncogene addiction. Cell 136: 823-837.

Mehta A, Singal AG (2015) Hepatocellular Carcinoma Surveillance: Does Alpha-Fetoprotein Have a Role? Gastroenterology 149(3): 816-817.

Sideras K, Bots SJ, Biermann K, Sprengers D, Polak WG, In IJ, De Man RA, Pan Q, Sleijfer S, Bruno MJ, Kwekkeboom J (2015) Tumour antigen expression in hepatocellular carcinoma in a low-endemic western area. Br J Cancer 112: 1911-1920.

Simpson AJ, Caballero OL, Jungbluth A, Chen YT, Old LJ (2005) Cancer/testis antigens, gametogenesis and cancer. Nat Rev Cancer 5: 615-625.

Sottoriva A, Kang H, Ma Z, Graham TA, Salomon MP, Zhao J, Marjoram P, Siegmund K, Press MF, Shibata D, Curtis C (2015) A Big Bang model of human colorectal tumor growth. Nat Genet 47 : 209-216.

Wang M, Li J, Wang L, Chen X, Zhang Z, Yue D, Ping Y, Shi X, Huang L, Zhang T, Yang L, Zhao Y, Ma X, Li D, Fan Z, Zhao L, Tang Z, Zhai W, Zhang B, Zhang Y (2015) Combined cancer testis antigens enhanced prediction accuracy for prognosis of patients with hepatocellular carcinoma. Int J Clin Exp Pathol 8: 3513-3528.

Xia QY, Liu S, Li FQ, Huang WB, Shi LN, Zhou XJ (2013) Sperm protein 17, MAGE-C1 and NY-ESO-1 in hepatocellular carcinoma: expression frequency and their correlation with clinical parameters. Int J Clin Exp Pathol 6: $1610-1616$.

Xu H, Gu N, Liu ZB, Zheng M, Xiong F, Wang SY, Li N, Lu J (2012) NY-ESO-1 expression in hepatocellular carcinoma: A potential new marker for early recurrence after surgery. Oncol Lett 3: 39-44.

*Correspondence: Dr F Grizzi; E-mail: Fabio.grizzi@humanitasresearch.it Published online 14 April 2016

(c) 2016 Cancer Research UK. All rights reserved 0007-0920/16

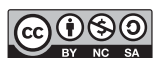

http://creativecommons.org/licenses/by-nc-sa/4.0/ 